\title{
Ceric ammonium nitrate catalysed three component one-pot efficient synthesis of 2,4,5-triaryl-1H-imidazoles
}

\author{
JAIPRAKASH N SANGSHETTI ${ }^{\mathrm{a}}$, NAGNNATH D KOKARE ${ }^{\mathrm{a}, \mathrm{b}}$, \\ SANDEEP A KOTHARKARA ${ }^{a}$ and DEVANAND B SHINDE ${ }^{\mathrm{a}, *}$ \\ ${ }^{a}$ Department of Chemical Technology, Dr Babasaheb Ambedkar Marathwada University, \\ Aurangabad 431004 \\ ${ }^{\mathrm{b}}$ Wockhardt Research Centre, New Drug Discovery, Aurangabad 431004 \\ e-mail: dbshinde.2007@gmail.com
}

MS received 27 April 2007; revised 24 July 2008

\begin{abstract}
Ceric ammonium nitrate $(\mathrm{CAN})$ is used as an efficient catalyst for the synthesis of 2,4,5triaryl-1H-imidazoles via condensation of benzoin/benzil, ammonium acetate, and aromatic aldehydes. The easy work-up, higher yields and shorter reaction time are the advantages of the method presented here.
\end{abstract}

Keywords. Ceric ammonium nitrate; triarylimidazoles; benzoin; benzil; ammonium acetate; aromatic aldehydes.

\section{Introduction}

Interest in imidazole-containing structures stems from their widespread biological activities and their use in synthetic chemistry. The imidazole ring system is one of the most important substructures found in a large number of natural products and pharmacologically active compounds. ${ }^{1-5}$ In recent years, substituted imidazoles are substantially used in ionic liquids, ${ }^{6}$ that has been given a new approach to 'Green Chemistry'. Triarylimidazole derivatives have many biological activities, for example, herbicidal, ${ }^{7}$ fungicidal, ${ }^{8}$ antiinflammatory, ${ }^{9}$ and antithrombotic activities. ${ }^{10}$ In addition, they are used in photography as photosensitive compound. ${ }^{11}$ Literature survey reveals that there are several methods for synthesizing them, mainly using nitriles and esters ${ }^{12-14}$ as the starting materials. The first synthesis of the imidazole core 2,4,5triphenylimidazoles using 1,2-dicarbonyl compounds aldehydes and ammonia, was proposed by Japp and Radziszewski. ${ }^{15,16}$ Subsequently, many other methods for synthesis of this important heterocycle have been published. ${ }^{17-18}$ Recently some methods for synthesis of tetra-substituted imidazoles are reported. ${ }^{19}$ However, some of these previous methods have suffered from one or more drawbacks like high temperature

*For correspondence requirement, highly acidic conditions, and the use of metal cyanides for preparation of the nitrile compounds that limit their utility. ${ }^{20,21}$ Some methods have resorted to harsh conditions (e.g. the formamide synthesis, which requires excess reagents, $\mathrm{H}_{2} \mathrm{SO}_{4}$ as a condensing agent, $\left.150-200^{\circ} \mathrm{C}, 4-6 \mathrm{~h}, 40-90 \%\right)^{22-24}$ For this reason, the development of mild, efficient and versatile method is still important.

Ceric (IV) ammonium nitrate (CAN) is a convenient and widely used reagent for affecting a wide array of synthetic transformations due to its many advantages such as solubility in organic solvents, low toxicity, high reactivity, and ease of handling. Although Ce (IV) derivatives are generally employed as one electron oxidants, the use of CAN as lewis acid in $\mathrm{C}-\mathrm{C}$ bond forming reaction has attracted great deal of attention. ${ }^{25}$ In continuation of our ongoing research for the development of simple and efficient methods for the synthesis of various heterocyclic compounds ${ }^{26}$ here, we present a simple, mild and efficient protocol for synthesis of 2,4,5triaryl-1H-imidazoles using CAN catalyst.

\section{Experimental}

${ }^{1} \mathrm{H}$ NMR spectra were recorded on a $400 \mathrm{MHz}$ Varian-Gemini spectrometer and are reported as parts per million ( $\mathrm{ppm})$ downfield from a tetramethylsi- 
lane internal standard. The following abbreviations are used; singlet $(s)$, doublet $(d)$, triplet $(t)$, quartet $(q)$, multiplate $(m)$ and broad $(b r)$. Mass spectra were taken with Micromass - QUATTRO-II of WATER mass spectrometer. HPLC was performed using Zorbax SB-C18 reverse phase column $(0.46 \times 25 \mathrm{~cm})$ on Shimadzu instrument equipped with an automatic injector with UV-PDA detector. Detection was carried out at $254 \mathrm{~nm}$. The mobile phase consists of $0.05 \%$ TFA and acetonitrile $(1: 1, \mathrm{v} / \mathrm{v})$. The products were eluted at flow rate of $1 \mathrm{ml} / \mathrm{min}$ using isocratic method. Flash column chromatography was performed with 300 and 400 meshes silica gel and analytical thin layer chromatography was performed on pre-coated silica gel plates $(60 \mathrm{~F}$ 254) with system ( $\mathrm{v} / \mathrm{v})$ indicated. Melting points were determined in capillary tubes and are uncorrected.

\subsection{Typical procedure}

A mixture of ceric ammonium nitrate $(10 \mathrm{~mol} \%)$, ammonium acetate $(40 \mathrm{mmol})$, and benzil or benzoin $(10 \mathrm{mmol})$ was dissolved in ethanol-water $(20 \mathrm{ml}$, $1: 1, \mathrm{v} / \mathrm{v})$ and to the reaction mixture, aromatic aldehyde $(12 \mathrm{mmol})$ was added. Then, the reaction mixture was heated at $65^{\circ} \mathrm{C}$ till completion of reaction as indicated by TLC. The reaction mixture was cooled to room temperature and poured on ice-water $(50 \mathrm{ml})$ to get the precipitated solid. It was collected by filtration, washed with water and dried to give the corresponding 2,4,5-triaryl-1H-imidazoles.

All synthesized compounds were characterized with ${ }^{1} \mathrm{H}$ NMR and mass. Also the melting points recorded and compared with the corresponding literature m.p. and found to be matching with those. The representative analytical data for 2,4,5-triphenyl-1H-

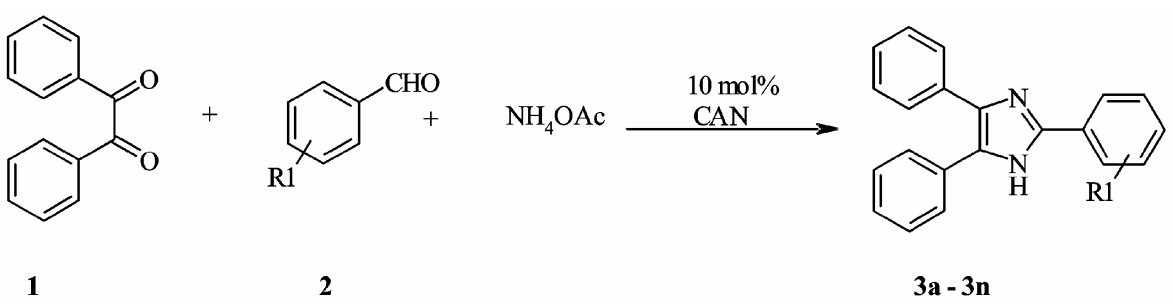

Scheme 1. Synthesis of 2,4,5-triarylimidazoles using benzil, aromatic aldehydes, ammonium acetate and $10 \mathrm{~mol} \%$ CAN catalyst.

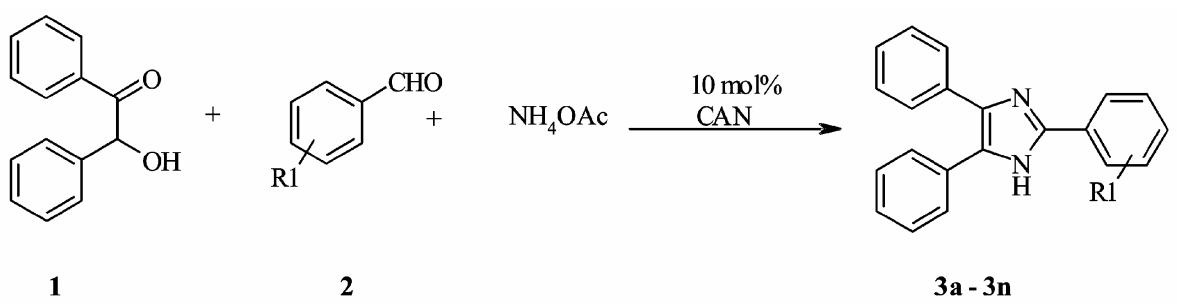

Scheme 2. Synthesis of 2,4,5-triarylimidazoles using benzoin, aromatic aldehydes, ammonium acetate and $10 \mathrm{~mol} \%$ Cerric ammonium nitrate catalyst.

Table 1. Optimization of reaction conditions and mol\% of CAN for the synthesis of 2,4,5-triphenyl-1H-imidazole (3a).

\begin{tabular}{lccc}
\hline Solvent & Mol\% CAN & Reaction time (min) & Yield (\%) \\
\hline Acetonitrile & 20 & 70 & 75 \\
Ethanol & 20 & 50 & 98 \\
Acetonitrile-water $(1: 1)$ & 20 & 70 & 75 \\
Ethanol-water $(1: 1)$ & 20 & 50 & 98 \\
Ethanol-water $(1: 1)$ & 15 & 50 & 98 \\
Ethanol-water $(1: 1)$ & 10 & 50 & 98 \\
Ethanol-water $(1: 1)$ & 5 & 70 & 87 \\
Ethanol-water $(1: 1)$ & $2 \cdot 5$ & 90 & 80 \\
\hline
\end{tabular}


Ceric ammonium nitrate catalysed three component one-pot efficient synthesis of 2,4,5-triaryl-1H-imidazoles 465

Table 2. Synthesis 2,4,5-triaryl-1H-imidazoles using benzil or benzoin, ammonium acetate, aromatic aldehydes, and $10 \mathrm{~mol} \% \mathrm{CAN}$.

\begin{tabular}{|c|c|c|c|c|c|c|}
\hline \multirow[b]{2}{*}{ Entry } & \multirow[b]{2}{*}{ Product } & \multirow[b]{2}{*}{$\mathrm{Ar}-\mathrm{CHO}$} & \multicolumn{2}{|c|}{$\begin{array}{l}\text { Reaction time } \\
\text { (min) }\end{array}$} & \multicolumn{2}{|c|}{$\begin{array}{c}\text { Yield }(\%) \\
(\text { Literature yield })^{29}\end{array}$} \\
\hline & & & Benzil & Benzoin & Benzil & Benzoin \\
\hline 1 & $3 \mathbf{a}$ & & 50 & 70 & $98(97)$ & $90(88)$ \\
\hline 2 & $3 b$ & & 50 & 80 & $96(93)$ & $85(85)$ \\
\hline 3 & $3 c$ & & 50 & 70 & $96(86)$ & $87(81)$ \\
\hline 4 & 3d & & 70 & 110 & $85(86)$ & $65(70)$ \\
\hline 5 & $3 e$ & & 60 & 70 & $95(93)$ & $90(91)$ \\
\hline 6 & $3 f$ & & 50 & 70 & $95(93)$ & $85(76)$ \\
\hline 7 & $3 g$ & & 60 & 70 & $95(95)$ & $86(88)$ \\
\hline 8 & $3 h$ & & 50 & 70 & $98(92)$ & $88(84)$ \\
\hline 9 & $3 \mathbf{i}$ & & 50 & 70 & $98(98)$ & $90(93)$ \\
\hline 10 & $3 \mathbf{j}$ & & 50 & 80 & $98(95)$ & $90(91)$ \\
\hline 11 & $3 \mathbf{k}$ & & 50 & 70 & $95(94)$ & $85(84)$ \\
\hline 12 & 31 & & 50 & 70 & $94(94)$ & $80(85)$ \\
\hline 13 & $3 m$ & & 50 & 70 & $95(92)$ & $84(80)$ \\
\hline 14 & $3 n$ & & 50 & 70 & $90(88)$ & $80(76)$ \\
\hline
\end{tabular}


Table 3. Synthesis of bis-2,4,5-triaryl-1H-imidazoles using benzil or benzoin, ammonium acetate, benzene-1,4-dicarboxaldehyde and $10 \mathrm{~mol} \% \mathrm{CAN}$.

Entry Product

imidazole (3a): Off-white solid, m.p. $276-277^{\circ} \mathrm{C}$; HPLC purity - 98.5\%; ${ }^{1} \mathrm{H}$ NMR (400 MHz, DMSO): $\delta=7.51-7.64(m, 6 \mathrm{H}), 7.67-7.73(m, 3 \mathrm{H}), 7.85-$ $7.90(m, 6 \mathrm{H}), 8.9(b s, 1 \mathrm{H}) ; \mathrm{MS}(\mathrm{EI}, 70 \mathrm{eV}): m / z=$ $296[\mathrm{M}+\mathrm{H}]^{+}$.

2-(4-chlorophenyl)-4,5-diphenyl-1H-imidazole (3f): Off-white solid, m.p. $196-198^{\circ} \mathrm{C}$; HPLC purity 97.0\% ${ }^{1} \mathrm{H}$ NMR $\left(400 \mathrm{MHz}, \mathrm{CDCl}_{3}\right): \quad \delta=7.4-7.60$ $(m, 6 \mathrm{H}), 7 \cdot 67-7.70(m, 2 \mathrm{H}), 7.93-8.0(m, 6 \mathrm{H}), 8.71$ $(b s, 1 \mathrm{H}) ; \mathrm{MS}(\mathrm{EI}, 70 \mathrm{eV}): m / z=330[\mathrm{M}+\mathrm{H}]^{+}$.

1,4-di[4,5-di (4-chloro phenyl) imidazol-yl] benzene (3p) m.p. $232-233^{\circ} \mathrm{C}$; HPLC purity $-97.5 \%$ ${ }^{1} \mathrm{H}$ NMR (400 MHz, DMSO): $\delta=7.6(d, J=8.39 \mathrm{~Hz}$, $8 \mathrm{H}), 7.37(d, J=8.43 \mathrm{~Hz}, 8 \mathrm{H}), 7.56(s, 4 \mathrm{H}), 7.67$ $(m, 2 \mathrm{H})$; MS (EI, $70 \mathrm{eV}): m / z=515[\mathrm{M}+\mathrm{H}]^{+}$.

\section{Results and discussion}

Initially, to study the catalytic efficiency of CAN, and to establish optimum quantity of CAN, synthesis of 2,4,5-triphenyl-1H-imidazole (3a) was carried out using benzil, ammonium acetate and benzaldehyde in different solvents and various mol\% of CAN (scheme 1). The title compound 3a was isolated with $98 \%$ yield using optimized reaction conditions (table 1), (ethanol-water $(1: 1)$ solvent and $10 \mathrm{~mol} \% \mathrm{CAN}$ catalyst). Using the standardized reaction conditions, a range of 2-aryl-4,5-diphenylimidazoles were synthesized and the results were summarized in table 2 . The method was found to be effective for heteroaromatic aldehydes for the synthesis 2-heteroaryl4,5-diphenylimidazoles with better yields (3i-3n). The easy work-up is advantageous aspect of this method, which includes the pouring of the reaction mixture over ice-water to get the precipitated solid which on filteration gave the sufficiently pure compound in good yield. The present method is superior to the available methods with regard to yields and reaction time. ${ }^{14}$ Especially, for the preparation of 4methylphenyl-2,4-diphenylimidazole (3h) was synthesized in $98 \%$ while the reported yield was $74 \%$ and also 2-chlorophnyl-2,4-diphenylimidazole (3b) was synthesized in $96 \%$ while the reported yield was $85 \%{ }^{27}$

1,2-diketones (like benzil) are usually prepared from the $\alpha$-hydroxy ketones (like benzoin) catalysed by various oxidants. Some of these catalysts are toxic, costly and also required the tedious experimental procedures. ${ }^{28}$ To avoid the preparation of starting material 1,2-diketones like benzil, the synthesis of 2,4,5-triphenyl-1H-imidazole was studied using benzoin (scheme 2). Surprisingly, using the similar reaction conditions, 2,4,5-triphenyl-1H-imidazole was isolated in $90 \%$ yield. Encouraged by this result, we extended the methodology for synthesis of various 2,4,5-triaryl-1H-imidazoles using benzoin and various aromatic aldehydes. The yields obtained were in the range of $65 \%$ to $90 \%$.

Also same methodology was extended for the synthesis of the substituted 1,4-di(4,5-diphenylimidazolyl) benzene (3o-3p) in the similar reaction conditions using benzoin, benzene 1,4 di-carboxaldehyde, ammonium acetate, and $10 \mathrm{~mol} \%$ CAN (table 3 ).

In conclusion we have presented use of CAN as a catalyst for efficient synthesis of 2,4,5-triaryl-1Himidazoles with moderate to excellent yields from 
benzil as well as benzoin. For all the presented reactions, the ethanol-water solvent was used which is relatively environmentally benign and supporting to Green Chemistry. The advantages of the reported method are the use of cheap, mild, and easily available catalyst, easy work-up, and better yields.

\section{Acknowledgement}

The authors are thankful to the Head, Department of Chemical Technology, Dr Babasaheb Ambedkar Marathwada University, Aurangabad for providing the laboratory facility.

\section{References}

1. Heers J, Backx L J J, Mostmans J H and Van Cutsem J 1979 J. Med. Chem. 221003

2. Hunkeler W, Mohler H, Pieri L, Polc P, Bonetti E P, Cumin R, Schaffner R and Haefely W 1981 Nature 290514

3. Brimblecombe R W, Duncan W A M, Durant G J, Emmett J C, Ganellin C R and Parons M E $1975 \mathrm{~J}$. Int. Med. Res. 386

4. Tanigawara Y, Aoyama N, Kita T, Shirakawa K, Komada F, Kasuga M and Okumura K 1999 Clin. Pharmacol. Ther. 66528

5. Wauquier A, Van Den Broeck W A E, Verheyen J L and Janssen P A J 1978 Eur. J. Pharmacol. 47367

6. (a) Wasserscheid P and Keim W 2000 Angew. Chem. Int. Ed. Eng. 39 37872; (b) Bourissou D, Guerret O, Ggabbai F T and Bertrand G 2000 Chem. Rev. 100

7. Liebl R, Randte $\mathrm{R}$, Mildenberger $\mathrm{H}$, Bauer $\mathrm{K}$ and Bieringer H 1987 Chem. Abstr. 108 6018g

8. Pozherskii A F, Soldatenkov A T and Katritzky A Y 1997 Heterocycles in life and society (New York: Wiley) p. 179

9. Lombardino J G and Wiseman E H $1974 \mathrm{~J}$. Med. Chem. 171182

10. Phillips A P, White H L and Rosen S 1983 Eur. PatAppl. EP 58, 890, Sep. 1, 1982. Chem. Abstr. 98 $53894 \mathrm{z}$

11. (a) Satoru I Japn Kokkai Tokyo Koho JP 01, 117, 867, 10 May 1989. Chem. Abstr. 1989111214482

12. Grimmett M R 1984 In Comprehensive heterocyclic chemistry (eds) A R Katritzky and C W Rees (New York: Pergamon) 5457

13. Grimmett M R 1996 In Comprehensive heterocyclic chemistry (eds) A R Katritzky and C W Rees (New York: Pergamon) 377

14. Balalaie S, Arabanian A and Hashtroudi M S 2000 Monatsh. Chem. 131945

15. Radziszewski B 1882 Chem. Ber. 151493

16. Japp F R and Robinson H H 1882 Chem. Ber. 151268
17. Li B, Chiu C K F, Hank R F, Murry J, Roth J and Tobiassen H 2002 Org. Proc. Res. Dev. 6682

18. Zhang P F and Chen Z C 2001 Synthesis 142075

19. (a) Nagarapu L, Apuri S and Kantevari S 2007 Journal of Molecular Catalysis A Chemical 266 104; (b) Kidwai M and Mothsra P 2006 Tetrahedron Lett. 47 5029

20. Davidson D, Weiss M and Jelling M $1937 \mathrm{~J}$. Org. Chem. 2319

21. Zhang E J, Moran E J, Woiwode T F, Short K M and Mjalli A M 1996 Teterahedron Lett. 37351

22. Usyatinsky A Y and Khmelnitsky Y L 2000 Tetrahedron Lett. 415031

23. Wasserman $\mathrm{H} \mathrm{H}$, Long Y O, Zhang R and Parr J 2002 Tetrahedron Lett. $\mathbf{4 3} 3351$

24. Deprez P, Guillaume J, Becker R, Corbier A, Didierlaurent S, Fortin M, Frechet D, Hamon G, Heckmann B, Heitsch H, Kleemann H W, Vevert J P, Vincent J C, Wagner A and Zhang J $1995 \mathrm{~J}$. Med. Chem. 38 2357

25. (a) Hwu J R and King K Y 2001 Curr. Sci. 81 1043; (b) Nair V, Panicker S B, Nair L G, George T G and Augustine A 2003 Synlett. 156; (c) Dhakshinmoorty A Synlett. 3014; (d) Varala R, Enugala R, Sreelatha N and Adapa S R 2006 Synlett. 1009; (e) Varala R, Sreelatha N, Adapa S R 2006 Synlett. 1549; (f) Nair V, Mathew J and Prabhakaran J 1997 Chem. Soc. Rev. 127; (g) Nair V, Balagopal L, Rajan R and Mathew J 2004 Acc. Chem. Res. 21; (h) Nair V and Deepathi A 2007 Chem. Rev. 1862

26. (a) Kokare N D, Sangshetti J N and Shinde D B 2007 Synthesis 2829; (b) Kokare N D, Nagawade R R, Rane V P and Shinde D B 2007 Synthesis 4 766; (c) Kotharkar S A, Jadhav M R, Nagawade R R, Bahekar S S and Shinde D B 2005 Lett. Org. Chem. 2 398; (d) Bahekar S S and Shinde D B 2004 Tetrahedron Lett. 45 7999; (e) Bahekar S S, Kotharkar S A and Shinde D B 2004 Mendeleev. Commun. 2

27. Jian-Feng Z, Yuan-Zhi S, Yan-Ling Y and Shu-Jiang T 2005 Synth. Commun. 351369

28. (a) Weiss M and Abbel M $1948 \mathrm{~J}$. Am. Chem. Soc. 70 3666; (b) McKillop A, Swann B, Ford M E and Taylor E C 1973 J. Am. Chem. Soc. 95 3641; (c) Zhang G S, Shi Q Z, Chen M F and Cai K 1997 Synth. Commun. 27953

29. (a) Shaabani A, Rahmati A, Farhangi E, Badri Z, 2007 Catalysis Communications 1149; (b) Kidwai M, Mothsra P, Bansal V and Goyal R 2006 Monatshefte fur Chemie 137 1189; (c) Jian-Feng Zhou 2005 Synth. Commun. 35 1369; (d) Frantz E D, Morency L, Soheili A, Murry J A, Grabowski E J J and Tillyer R D 2004 Org. Lett. 6 843; (e) Liu J, Chem J, Zhao J, Zhao Y, Li L and Zhang H 2003 Synthesis 2661; (f) Weinmann H, Harre M, Koeing K, Merten E and Tilestam U 2002 Tetrahedron Lett. 43 593; (g) Sarshar S, Siev D and Mjalli A M M 1996 Tetrahedron Lett. 37835 